\title{
Effect of Water Deficit at Different Growth Phases of Peanut. II. Response to Drought During Preflowering Phase
}

\author{
R. C. Nageswara Rao, ${ }^{\star}$ J. H. Williams, M. V. K. Sivakumar, and K. D. R. Wadia
}

\begin{abstract}
Water deficits can affect peanut yields differentially depending on time of occurrence and intensity. Previous reports have shown that moderate water deficit during the preflowering phase increases pod yields by 13 to $19 \%$ relative to the fully irrigated control. This paper describes, in a more quantitative way, crop physiological factors that contribute to these increased yields. In the 1980 to 1981 and 1981 to 1982 postrainy seasons, a study was conducted on a medium deep Alfisol at the International Crop Research Institute for the SemiArid Tropics (ICRISAT) in central India, to examine the responses of peanut (Arachis hypogaea L.), cv. Robut 33-1, under three levels of soil water deficits during preflowering phase relative to an adequately irrigated control. Three intensities of drought were created (from 10-50 d after sowing [DAS]) using-line source sprinkler irrigation, while the control was irrigated at 10-d intervals. Moderate water deficits during the preflowering phase increased subsequent crop growth and pod growth rates in 1980 to 1981 but not in 1981 to 1982. Differences in flowering and total pod numbers between treatments were relatively small when compared to the subsequent differences in pod setting and maturity. In both seasons, greater synchrony of pod set in the moderately stressed plots resulted in a greater proportion of mature pods at final harvest. The most severely stressed plot had lower yields despite adequate irrigation subsequent to the preflowering water deficits.
\end{abstract}

Additional Index Words: Arachis hypogaea L., Line-source irrigation, Preflowering phase, Stomatal conductance, Crop growth analysis.

$\mathrm{P}$ EANUT is widely grown under rainfed conditions in the semiarid tropical regions. Erratic and limited rainfall seriously limits crop productivity in these regions. Where a limited water source is available, supplementary irrigation is practiced. However, to optimize the returns on limited water resources, more knowledge on crop response to water deficits at different crop growth stages is needed. Boote et al. (4) have extensively reviewed the work on the effects of different timings of water deficits on vegetative and reproductive growth of peanut. Water deficits during the pod filling phase are more damaging to yield than droughts during the pod addition phase $(2,10,12)$. Information available on the effect of water deficits during the vegetative phase indicate minimal effects on peanut growth and yield $(9,13,18,19)$. However, in a previous paper, Nageswara Rao et al. (10) observed that moderate drought during the preflowering phase increased pod yields of cv. Robut 33-1 by 13 to $19 \%$, relative to the regularly irrigated control. The objective of this paper is to examine the effect of preflowering water deficit on crop growth and development

R.C. Nageswara Rao, J.H. Williams, and K.D.R. Wadia, Legumes Program, Int. Crops Res. Inst. for the Semi-Arid Tropics (ICRISAT), Patancheru, Andhra Pradesh, India 502324; M.V.K. Sivakumar, ICRISAT Sahelian Ctr., B.P. 12404, Niamey, Niger. Submitted as Journal Article no. 634 by ICRISAT. Received 30 Oct. $1986 .{ }^{*}$ Corresponding author.

Published in Agron. J. 80:431-438 (1988). to identify crop physiological factors associated with the observed yield responses.

\section{MATERIALS AND METHODS}

The experiment was conducted at the ICRISAT center near Hyderabad, India $\left(17^{\circ} 32^{\prime} \mathrm{N} 78^{\circ} 16^{\prime} \mathrm{E}\right)$ during the postrainy season (November-April) of 1980 to 1981 (first season) and 1981 to 1982 (second season). Details about the experimental site, soil treatments, and crop management have been described by Nageswara Rao et al. (10).

The seeds of a Virginia bunch type cultivar, Robut 33-1, were sown on 8 Nov. 1980 and 9 Nov. 1981 for the first and second season experiments in a medium deep Alfisol at $0.1-\mathrm{m}$ intervals in four rows spaced $0.3 \mathrm{~m}$ apart on beds 1.2 $m$ wide. After sowing, the field was irrigated to field capacity using perforated tubes that distributed water uniformly in a given plot; afterwards, $50 \pm 2 \mathrm{~mm}$ of irrigation was applied to the control at $10-d$ intervals $(10)$, while another treatment (10) received differential irrigation amounts $\mathrm{A}, \mathrm{B}$, and $\mathrm{C} 10$ and $21 \mathrm{~d}$ after sowing (DAS) using line-source sprinkler irrigation (8). Between 21 and 50 DAS, no further irrigation was applied to T2 (Tables 1 and 2). From 51 DAS all treatments were irrigated uniformly with about $50 \mathrm{~mm}$ of water at 10-d intervals during January and February, but the frequency was increased to 7-d intervals in March to meet increased evaporative demands. The amount of water applied to each plot was measured for each irrigation by placing plastic catch-cans in at least two locations. Treatments were replicated three times in both seasons.

Flower Counts. In the 1980 to 1981 season, five plants were randomly selected in each plot and marked for daily flower counts. The number of fresh flowers were counted daily in the morning from the day of first flower appearance until final harvest.

Growth Analysis. Crop growth analysis was conducted in each plot on plants harvested from a ground area of 0.75 $\mathrm{m}^{-2}$ at weekly (first season) or bi-weekly (second season) intervais, starting at $2 \mathrm{wk}$ after sowing. In the first season, the sampling for growth analysis in the control was done 2 or $3 \mathrm{~d}$ later than in the treatments for convenience in processing samples. The plants were washed to remove attached soil, and a subsample of three plants was picked at random for detailed analysis. The rest of the plants were treated as a bulk sample.

Bulk Sample Measurements. Plants from the bulk sample were separated into leaves, stems, and immature and mature pods. These components were oven-dried at $80^{\circ} \mathrm{C}$ for $48 \mathrm{~h}$. The immature and mature pods were shelled and their kernel weights determined after oven drying.

Subsample Measurements. Subsample plants were separated into leaves, stems, roots, and reproductive structures. The main stem length and number of branches were recorded. A random sample was taken from the leaf fraction for leaf area measurement with a LI-3100' automatic leaf area meter (LI-COR, Inc., Lincoln, NE). Total leaf area for each sampling was calculated as the product of the leaf area/ dry weight ratio of the random leaf sample and the total leaf weight (leaf weight of the subsample plus leaf weight of the bulk sample). The leaf area index (LAI) was calculated as the ratio of total leaf area to harvested ground are $\left(0.75 \mathrm{~m}^{-2}\right)$. Reproductive parts were divided into aerial pegs, subterra-

'Mention of commercial products or companies does not imply endorsement or recommendation by ICRISAT of these over others of similar nature. 
Table 1. Timing of irrigation and amounts of water applied during the treatment period in the 1980 to 1981 growing season. $\dagger$

\begin{tabular}{|c|c|c|c|c|c|}
\hline \multirow[b]{3}{*}{ Date } & \multirow[b]{3}{*}{ DAS } & \multicolumn{4}{|c|}{ Water applied to each treatment } \\
\hline & & \multirow{2}{*}{$\begin{array}{c}\text { T1 } \\
\text { Control }\end{array}$} & \multicolumn{3}{|c|}{$\mathbf{T} 2$} \\
\hline & & & A & B & C \\
\hline & & & - & & \\
\hline 8 Nov. 1980 & 0 & FC & FC & FC & FC \\
\hline 19 Nov. 1980 & 11 & 50 & 50 & 20 & 5 \\
\hline 29 Nov. 1980 & 21 & 50 & 50 & 20 & 5 \\
\hline 9 Dec. 1980 & 31 & 50 & - & -- & -- \\
\hline 19 Dec. 1980 & 41 & 50 & -- & -. & .. \\
\hline 29 Dec. 1980 & 51 & 50 & 50 & 50 & 50 \\
\hline TW & & 725 & 630 & 580 & 550 \\
\hline
\end{tabular}

$\dagger$ DAS $=$ days after sowing. $F C=$ irrigation to field capacity $(100 \pm 10$ $\mathrm{mm}$ ) using perforated tubes. SE for $50-\mathrm{mm}$ irrigations was $\pm 2 \mathrm{~mm}$; for 20 -mm irrigation, $\pm 1.8 \mathrm{~mm}$; for $5 \mathrm{~mm}$ írrigation, $\pm 1.1 \mathrm{~mm}$. $\mathrm{TW}=$ total amount of water ( $\mathrm{mm}$ ) applied during the growing season.

nean pegs, juvenile pods, immature pods, and mature pods as described by Williams et al. (21). The numbers in each class were counted and weights recorded after oven-drying. The pods were shelled and the kernel weights were determined.

Crop (CGR) and pod (PGR) growth rates were estimated starting from the time of measurable seed growth ( 80 and 68 DAS in the first and second season, respectively) until final harvest, using linear regression on sequential harvest data. Pod weights were adjusted for their higher energy content by multiplying by a factor coefficient of 1.65 as suggested by Duncan et al. (5). The partitioning factor (PF) was then calculated (given below) as the rate of the PGR (energy adjusted) as a percentage of the contemporary CGR during pod fill. Calculation of CGR was based on the biomass of the shoot plus the pod (energy adjusted).

$$
\mathrm{PF}=(\mathrm{PGR} \times 1.65 / \mathrm{CGR}) \times 100 .
$$

The crop growth and development data presented are mostly from the 1980 to 1981 season as more measurements were taken in this season, but data from the 1981 to 1982 season are also presented as supporting evidence where necessary.

Stomatal Conductance and Canopy Temperature Measurements. Stomatal conductance was measured on a fully exposed and fully expanded third or fourth leaf from the main shoot apex using a steady state porometer (Model LI 1600;' LI-COR, Inc.). Measurements were made on the adaxial and abaxial sides of five leaves selected randomly in each plot between 1300 to $1400 \mathrm{~h}$ IST each day from 35 DAS until final harvest. Leaf conductances measured on each day were averaged over 5 -d periods. Canopy temperatures were measured (at five locations in each plot) every day along with stomatal conductance measurements, with a $2.8^{\circ}$ field-of-view Barnes 14-220-1 ${ }^{1}$ infrared thermometer (Barnes Engineering Co., Stamford, CT). The instrument was held at an angle of $45^{\circ}$ to the crop surface at a distance of $0.5 \mathrm{~m}$ so as to obtain a canopy temperature minimally influenced by the underlying soil. Air temperature was measured $1 \mathrm{~m}$

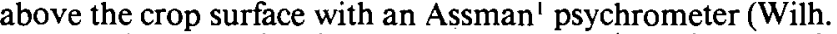
Lambrecht KG, Gottingen, West Germariy): Canopy-air temperature differential was calculated every day for each treatment, and this value was cumulated over the crop growth period to give the cumulative canopy-air temperature differential (CCTD).

\section{RESULTS AND DISCUSSION}

In both seasons maximum air temperature was about $28^{\circ} \mathrm{C}$ at sowing time and increased gradually to $37^{\circ} \mathrm{C}$ at crop maturity. Temperatures started rising only from the fourth standard week (22-28 January)
Table 2. Timing of irrigation and anounts of water applied during the treatment period in the 1981 to 1982 growing season. $\dagger$

\begin{tabular}{|c|c|c|c|c|c|}
\hline \multirow[b]{3}{*}{ Date } & \multirow[b]{3}{*}{ DAS } & \multicolumn{4}{|c|}{ Water applied to each treatment } \\
\hline & & \multirow{2}{*}{$\begin{array}{c}\text { T1 } \\
\text { Control }\end{array}$} & \multicolumn{3}{|c|}{$\mathbf{T} 2$} \\
\hline & & & A & B & C \\
\hline & & & -- & & 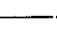 \\
\hline 9 Nov. 1981 & 0 & $\mathrm{FC}$ & FC: & FC & FC \\
\hline 19 Nov. 1981 & 13 & 50 & 50 & 20 & 5 \\
\hline 1 Dec. 1981 & 22 & 50 & 50 & 20 & $\mathbf{5}$ \\
\hline 11 Dec. 1981 & 32 & 50 & -. & -- & - \\
\hline 21 Dec. 1981 & 43 & 50 & -- & .. & - \\
\hline 31 Dec. 1981 & 52 & 50 & 50 & 50 & 50 \\
\hline TW & & 825 & 730 & 700 & 675 \\
\hline
\end{tabular}

$\dagger \mathrm{DAS}=$ days after sowing. $\mathrm{FC}=$ irrigation to field capacity $(100: 10$ $\mathrm{mm}$ ) using perforated tubes. SE for $50-\mathrm{mm}$ irrigations was $\pm 2 \mathrm{~mm}$; for $20-\mathrm{mm}$ irrigation, $1.8 \mathrm{~mm}$; for $5 \mathrm{~mm}$ irrigation, $\pm 1.1 \mathrm{~mm}$. TW = tota amount of water (mm) applied during the growing season.

in the first season due to a few rain showers (total of $10 \mathrm{~mm}$ ) during the second and third weeks of January. However, these rains had little effect on soil moisture status as they were spread over 2 wk. Also, interrnittent rains $(77 \mathrm{~mm})$ were received during 5 to 18 March (standard weeks 10 and 11). In the second season only $7 \mathrm{~mm}$ of rain fell during 26 March to 8 April (standard weeks 13 and 14), after the release of drought stress, and hence did not interfere with the treatments imposed. Meteorological data for the two growing seasons were reported by Nageswara Rao et al. (10).

Leaf Area Index. The pattern of LAI development (Fig. 1) was essentially similar in both seasons. Maximum LAI was achieved during mid-pod filling phase and was similar to that reported by Williams et al. (21), Enyi (7), and Boote et al. (3). Leaf area index decreased after 125 DAS.

Full ground cover was achieved in the control and treatments A and B by 90 to 95 DAS at LAI greater than 3 (5), but leaf area development in treatment $C$ was greatly reduced and complete cover was only achieved by 135 DAS. Treatment $C$ reached only $50 \%$ (in the first season) and 135 DAS. Treatment $C$ reached only $50 \%$ (in the first season) and $70 \%$ (in the second season) of LAI achieved by the control despite the fact that the majority of the leaf area was developed only after the release of water stress. Thus, water deincit created by only the most limited irrigation treatment was sufficient to influence the subsequent development of LAI. This limitation to leaf area development was possibly associated with the effect of early water deficits on branch initiation (Fig. 2).

Mainstem Length and Branching. Mainstem length and the number of branches continued to increase from sowing to maturity in the control and treatments $A$ and B (Fig. 2 and 3), but there were treatment differences in the rates of stem elongation and branch emergence. The stem elongation rate was lower in treatments A and B than in the control until 105 DAS, and thereafter was more rapid in treatments $A$ and $B$, intermediate in the control, and least in treatment C. Similar trends were also observed in 1981 to 1982 . This effect of drought has been reported by Ochs and Wormer (11). Water deficit is known to influence the current elongation process by affecting relative turgidity $(1,20)$. It is therefore likely that the differences in mainstem elongation between 50 and 120 DAS were 
due to a residual effect of early drought stress on physiological processes, possibly the effect of reduced cell division during the stress period. However, reduction in number of branches due to early season stress would also imply stress effects on cell division.

Reproductive Development. Reproductive development in peanut involves a sequential progression of flowering, peg growth to the soil surface, surface penetration, fruit initiation and filling. Water deficits during the preflowering phase had residual effects on many of these processes.
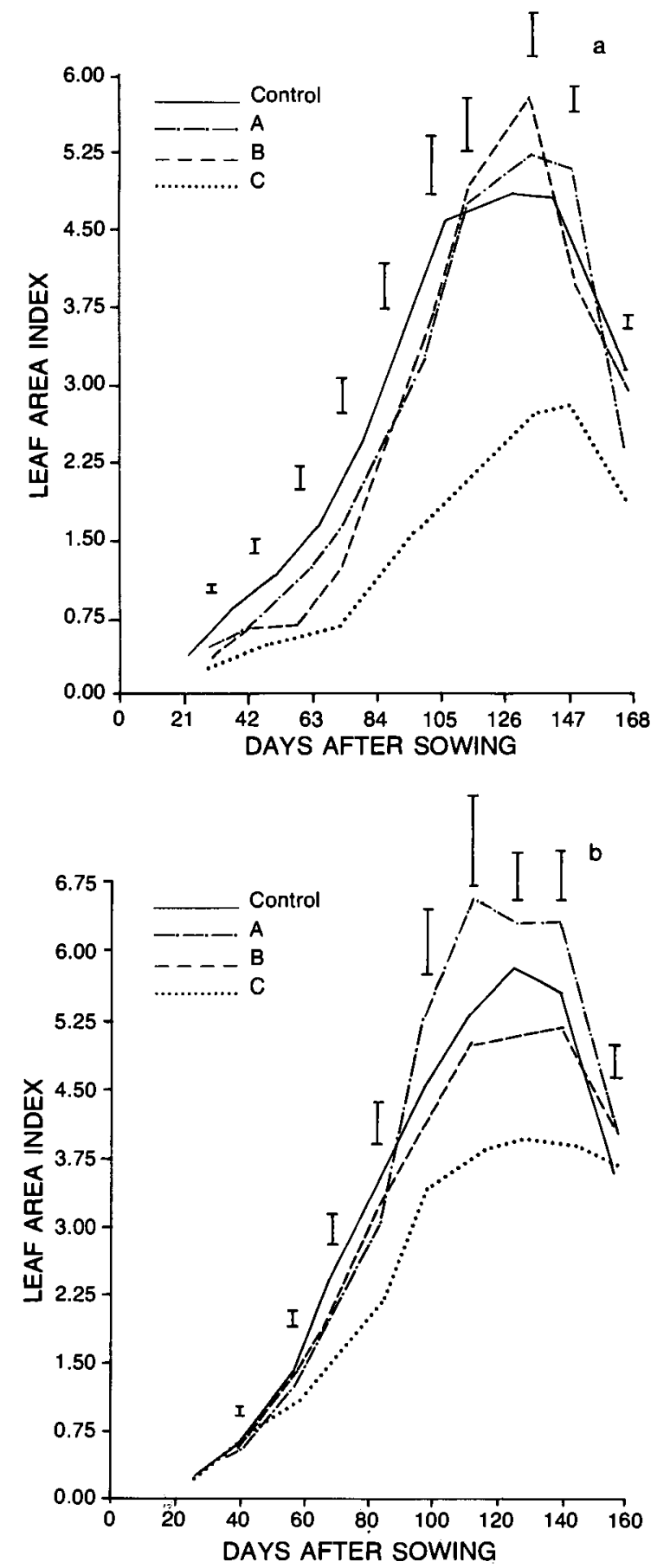

Fig. 1. Development of LAI as influenced by deficit irrigation during the preflowering phase in the (a) 1980-1981 and (b) 1981-1982 growing seasons. (Vertical bars indicate SE.)
Flowering. Flowering in the first season commenced at the same time in all treatments (Fig. 4). The rate of flower production was similar in all treatments until 105 DAS. Drought effects on flowering were evident thereafter. However, the rate of flower production after 105 DAS was reduced with an increase in the severity of early season drought stress. Since only 15 to $20 \%$ of flowers (usually the first initiated) result in pods that contribute to yield (17), the differences in cumulative flower number are not likely

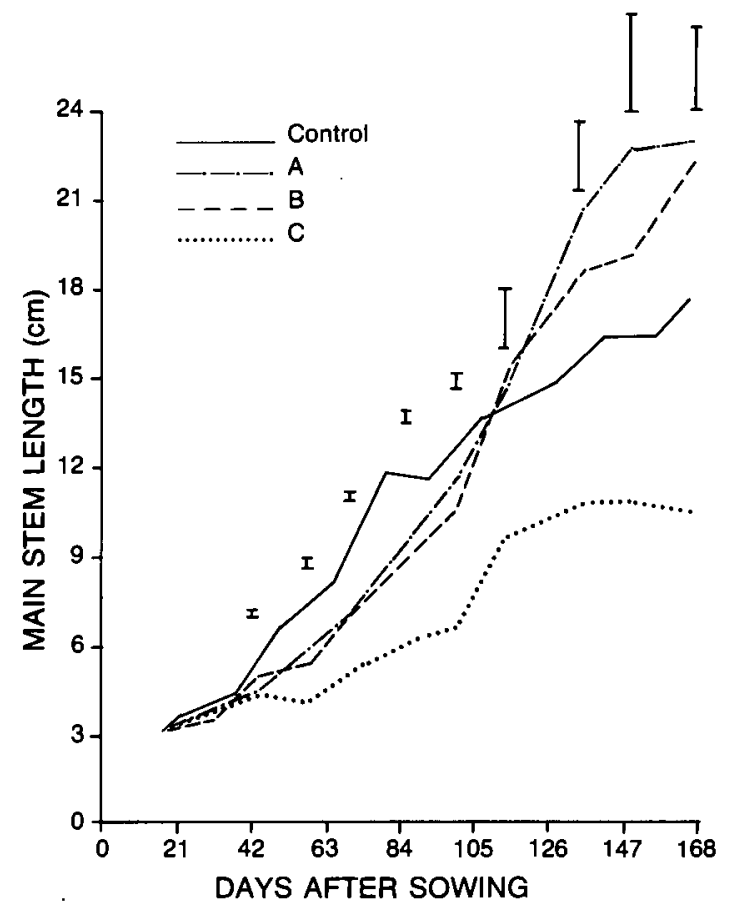

Fig. 2. Effect of water deficits during preflowering phase on the length of the main axis in the 1980-1981 growing season. (Vertical bars indicate SE.)

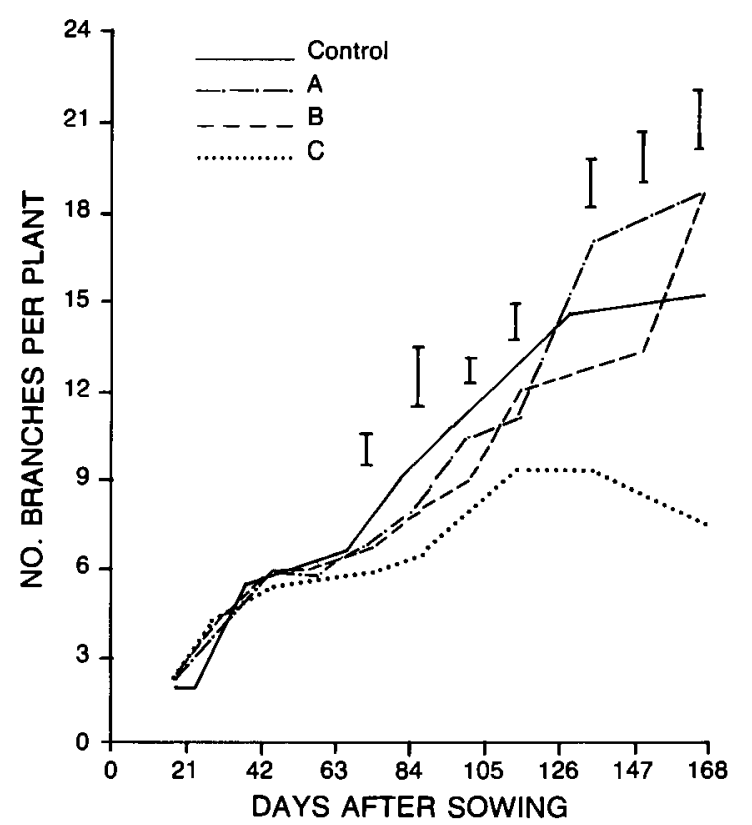

Fig. 3. Effect of water deficits during preflowering phase on the number of branches in the 1980-1981 growing season. (Vertical bars indicate $\mathrm{SE}$.) 


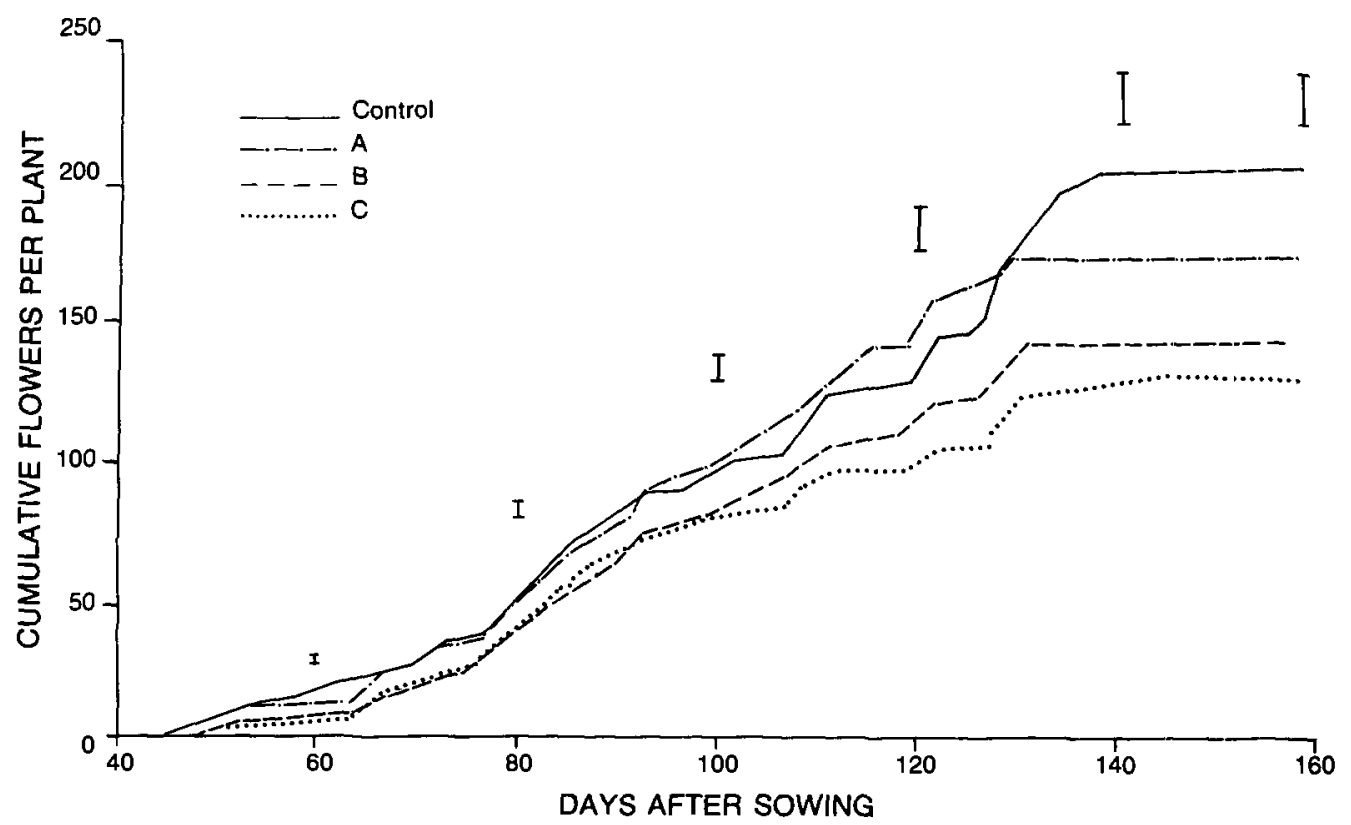

Fig. 4. Cumulative number of flowers as influenced by water deficits during the preflowering phase in the 1980-1981 growing season. (Vertical bars indicate $\mathrm{SE}$. )

to have influenced the yield responses to early water deficits, particularly so since the flowering differences between the treatments were small compared to the subsequent differences in pod set and maturity patterns.

Pegging. Data for peg number were variable between samples, but the proportion of pegs that penetrated the soil surface (Fig. 5a and b) was generally less in the control than in treatments A and B in both seasons, particularly before 80 DAS. Possibly, the promotion of vegetative growth under adequately irrigated conditions (6) may discourage penetration of a higher proportion of pegs into soil, due either to increased competition for assimilates or reduction in the

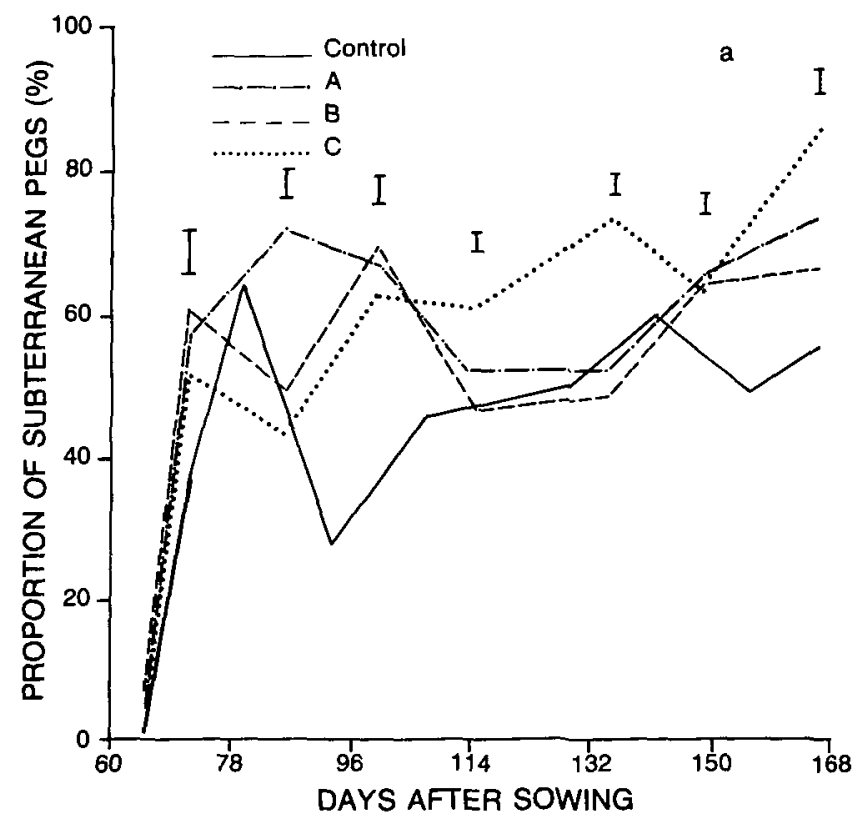

number of nodes from which pegs can reach the soil because of increased stem elongation (21). In either case, the reduction in vegetative growth and stem elongation in treatments $\mathrm{A}, \mathrm{B}$, and $\mathrm{C}$ was associated with increased numbers of fruit-bearing sites.

Pod Set. The total number of pods (Fig. 6a) and pods at different stages of maturity (Fig. 6b, c, and d) are shown only for the first season, but similar results were obtained for the second season. The pattern of pod initiation was substantially influenced by the drought stress treatments. Pod initiation was fastest in the water deficit treatments, particularly in treatment $C$, and both pod set rate and final pod number decreased as the stress level decreased (Fig. 6a). More

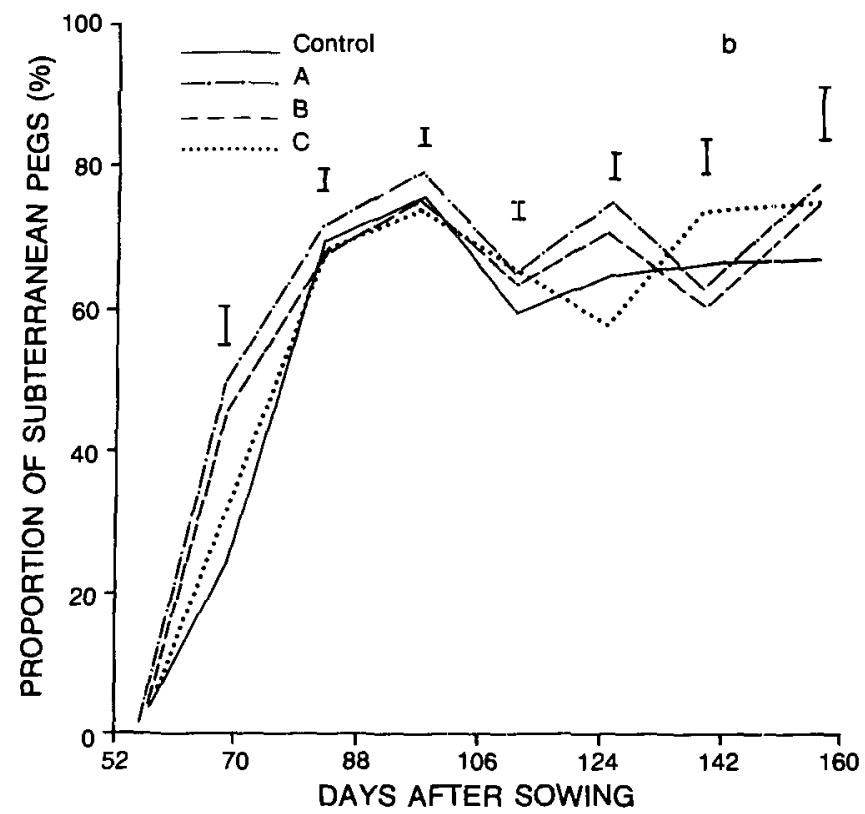

Fig. 5. Proportion of pegs (\%) that became subterranean in different treatments in the (a) 1980-1981 and (b) 1981-1982 growing seasons. (Vertical bars indicate SE.) 

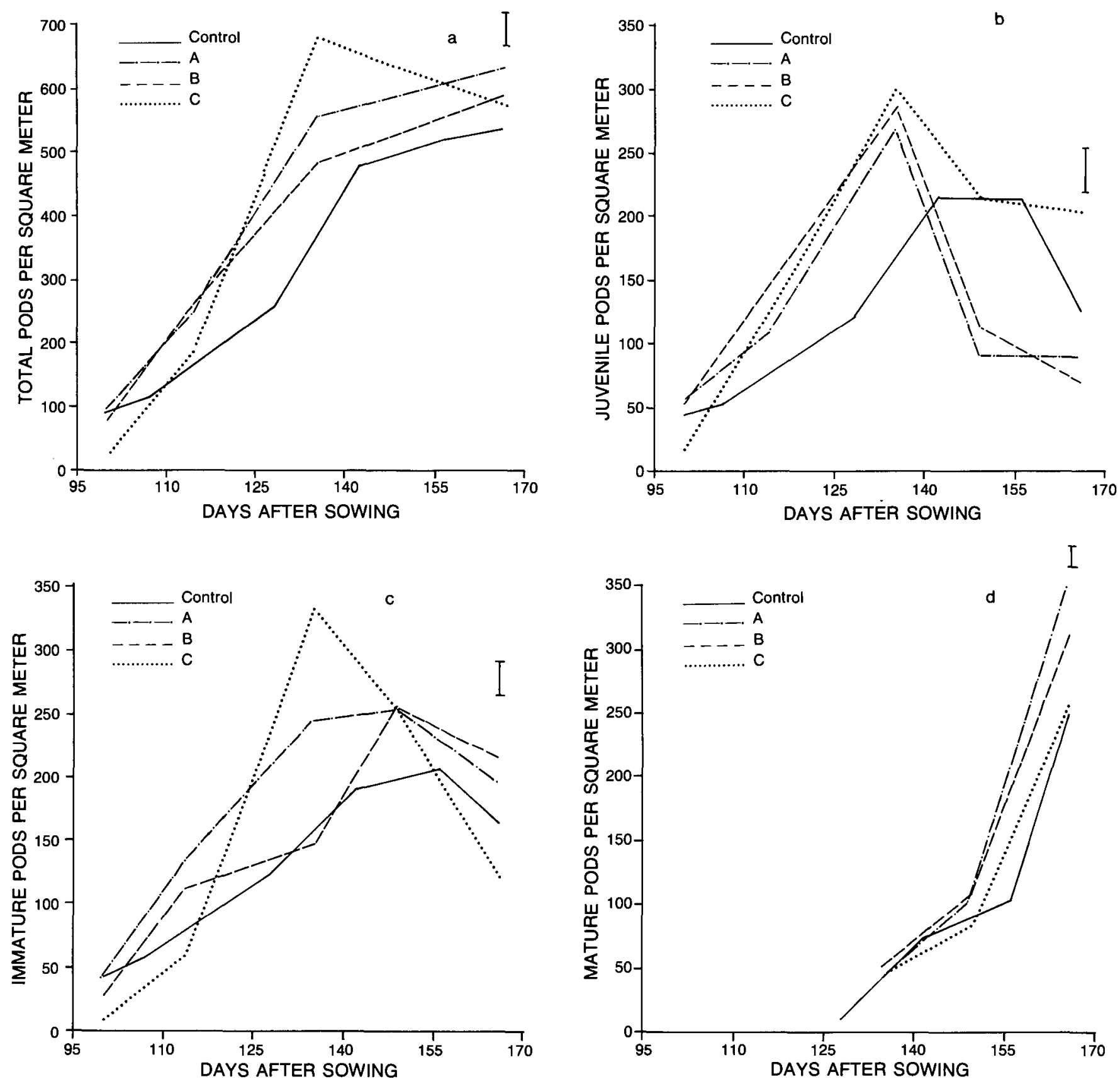

Fig. 6. Changes with time in the numbers of (a) total, (b) juvenile, (c) immature, and (d) mature pods in the 1980-1981 growing season. (Vertical bars indicate SE.)

juvenile pods were initiated before 135 DAS in all three stress treatments than in the control (Fig. 6b). However, after 135 DAS treatments A and B had fewer juvenile pods than the control since a greater number of these had progressed into immature pods (Fig. 6c). Although a large number of juvenile pods were initiated in treatment $C$, many of them developed no further, presumably because of limitations of assimilates associated with the lower LAI and CGR. It is significant that despite the presence of juvenile pods in $C$, not all assimilates were partitioned into reproductive growth over this period.

The highest number of immature pods were observed in treatment $C$ by 140 DAS, but the rapid re- duction in these by final harvest was not reflected in an increase in mature pods (Fig. 6d). Treatments A and $B$ had a higher number of mature pods than the control and treatment $\mathrm{C}$ by final harvest.

The proportion of subterranean pegs that subtended mature pods at final harvest was greatest in treatments $A$ and $B$ in both seasons (Fig. 7), although there was a greater sink potential in treatment $C$. It appears that extremely synchronous pod setting as in treatment $\mathrm{C}$ was also undesirable since the crop appeared to initiate more pods than it could subsequently fill.

Stomatal Conductance and Canopy Temperature. To show the effect of water stress on stomatal activity prior to and after release of water stress, sea- 

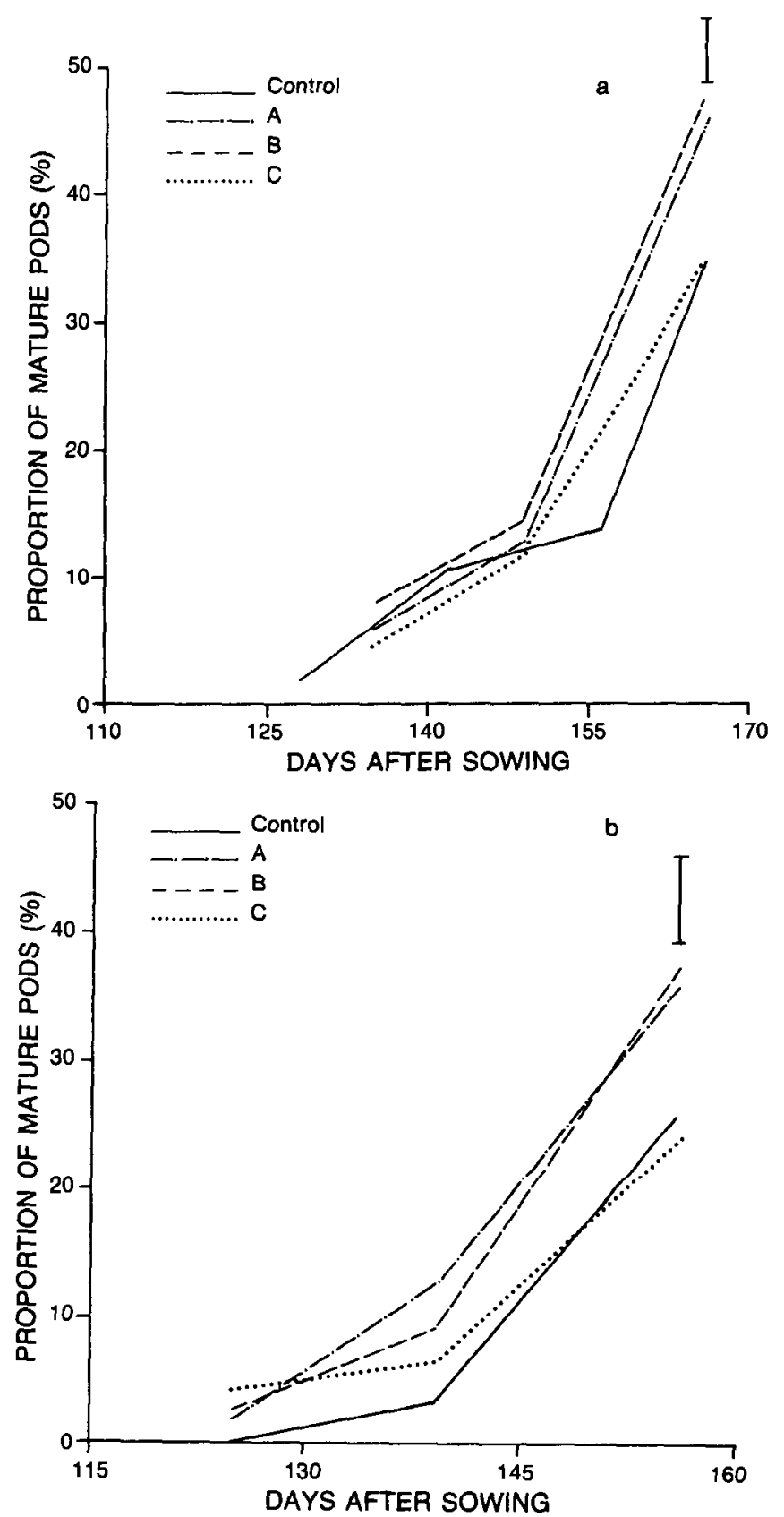

Fig. 7. Changes with time in the percentage of subterranean pegs that developed into mature pods in the (a) 1980-1981, and (b) 1981-1982 growing seasons. (Vertical bars indicate SE.)

sonal changes in stomatal conductance in different treatments are shown in Fig. 8. Stomatal conductance decreased with an increase in water deficit in treatments $B$ and $C$ during the deficit period from 30 to 50 DAS. This implies reduced assimilation rates. The control and treatment $\mathbf{A}$ had similar conductances until the release of water stress, after which treatment A had slightly higher conductances than the control. Although all treatments returned to regular irrigation at 50 DAS, treatment $C$ returned to comparable conductance levels only by 90 DAS. Sanders et al. (14) and Sivakumar and Sarma (16) have observed an increase in canopy temperature and a decrease in sto-

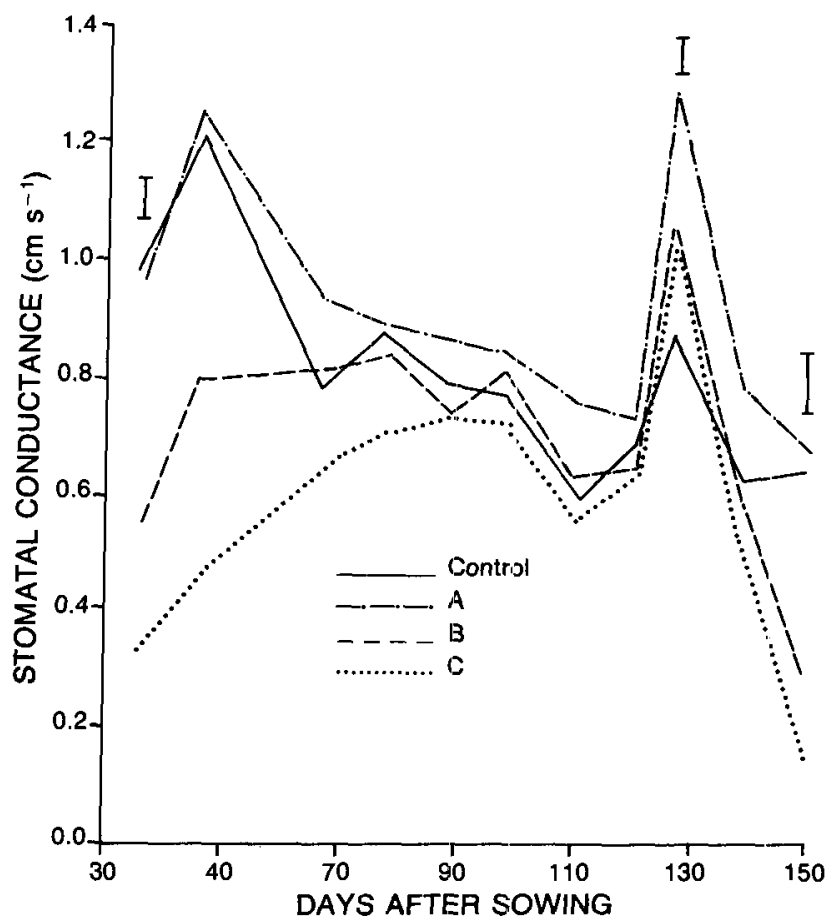

Fig. 8. Influence of preflowering water deficits on stomatal conductance in the 1980-1981 growing season (Vertical bars indicate SE.)

matal conductance associated with drought stress. An observed increase in stomatal conductance by 130 DAS was associated with rains around 123 DAS.

Cumulative canopy-air temperature differential indicates the relative ability of the crop to meet evaporative demand under different treatments. Treatment differences in CCTD were established in two phases, these being prior to and after 80 DAS in both seasons (Fig. 9). It is evident that all water stress treatments had higher CCTD than the control over the first period, reflecting the variations in water application and the resulting amounts of transpiration. The CCTD increased with an increase in stress level, with the highest being in treatment $C$. While the CCTD value at $80 \mathrm{DAS}$ in the control was $-310^{\circ} \mathrm{C}$, it was only $-75^{\circ} \mathrm{C}$ in treatment $\mathrm{C}$ in the first season. The corresponding values for the second season were -325 and $-115^{\circ} \mathrm{C}$. After 80 DAS, CCTD data confirmed the lower stomatal conductances in treatment $\mathrm{C}$, despite being returned to adequate irrigation. The higher canopy temperatures observed in $\mathrm{C}$ treatment over this phase might have been due partially, to incomplete ground cover resulting in a greater radiation load on leaves, and perhaps by decreased mutual shading.

The higher stomatal conductances measured during pod fill in treatments A and B compared to the control were possibly due to promotion of root growth by the early stress $(11,15)$ interacting with the differences in irrigation amounts between the years. The rise in stomatal conductance in the first season at 130 DAS, when the humidity increased, indicates that the water supply was generally inadequate to satisfy the transpirational demand. In the second season when irrigation was greater, these effects were less apparent, perhaps because there was less dependence on water from deeper horizons. 


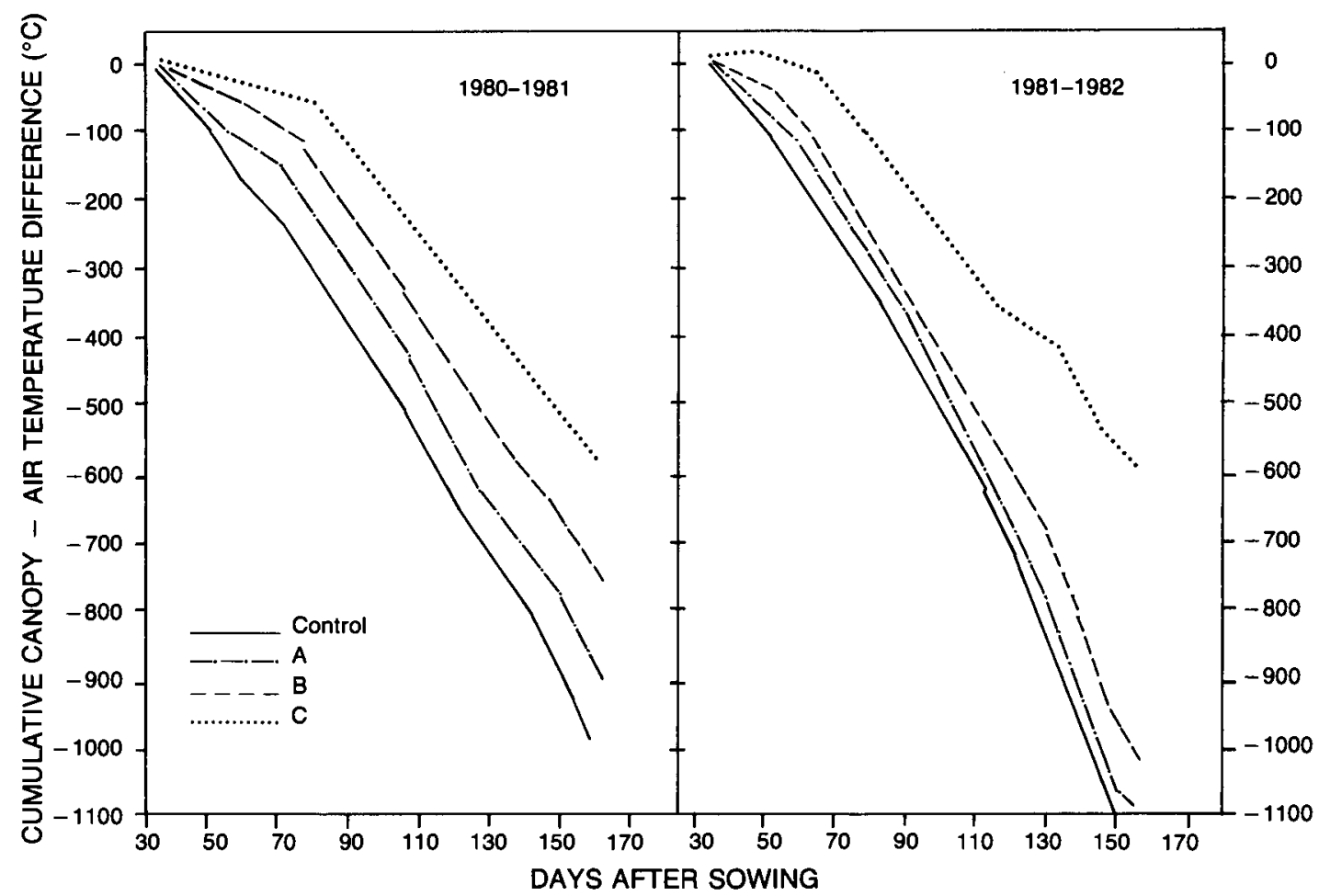

Fig. 9. Seasonal changes in the cumulative canopy-air temperature differential in the 1980-1981 and 1981-1982 growing seasons.

Crop Growth Rates and Partitioning. Pod yields of the four treatments in the first and second seasons are presented in Tables 3 and 4, respectively, along with stomatal conductance, growth rates, and partitioning. The CGRs were similar across seasons for the water stressed treatments, but the CGRs in the control differed substantially from the first to second year. Stomatal conductances and CGRs were higher on average in the second season, reflecting the greater amount of irrigation applied. The lower CGRs in treatment C were associated with lower stomatal conductances and higher canopy temperatures in both seasons. However, the reasons for the differences between the CGRs of the control and the treatments between years are not clear from the data collected. In the first season, higher stomatal conductance of treatment $A$ than the control during most of the crop's life explains higher CGRs in treatment A. However, the control and treat-

Table 3. Pod yields, mean stomatal conductance (SC), crop growth rate (CGR), pod growth rate (PGR), and partitioning factor (PF) after the initiation of pod growth (80-166 DAS) in the 1980 to 1981 season.

\begin{tabular}{|c|c|c|c|c|c|}
\hline Treatment & Pod yield & sc & CGR & PGR & $\mathrm{PF}$ \\
\hline & $\mathbf{k g ~ h a ^ { - 1 }}$ & $\mathrm{mm} \mathrm{s}^{-1}$ & \multicolumn{2}{|c|}{$-\mathrm{g} \mathrm{m}^{-2} \mathrm{~d}^{-1}-$} & $\%$ \\
\hline Control & 4615 & 6.9 & $\begin{array}{c}8.8 \\
(0.97) \dagger\end{array}$ & $\begin{array}{c}6.4 \\
(0.92)\end{array}$ & 73 \\
\hline A & 5480 & 8.3 & $\begin{array}{c}13.1 \\
(0.98)\end{array}$ & $\begin{array}{c}9.9 \\
(0.93)\end{array}$ & 76 \\
\hline B & 5040 & 7.0 & $\begin{array}{c}12.4 \\
(0.97)\end{array}$ & $\begin{array}{c}9.2 \\
(0.94)\end{array}$ & 74 \\
\hline $\mathrm{C}$ & 3687 & 6.7 & $\begin{array}{c}9.2 \\
(0.98)\end{array}$ & $\begin{array}{c}6.8 \\
(0.93)\end{array}$ & 74 \\
\hline $\operatorname{LSD}(0.05)$ & 572 & 1.48 & 2.75 & 2.44 & 4.6 \\
\hline
\end{tabular}

$\dagger$ Values in parenthesis for CGRs and PGRs are $R^{2}$ of the regressions between DAS and respective dry matter.

$\ddagger$ LSD for the difference between the treatments. ment B had similar stomatal conductances but differed in CGR.

In the first season, measurable seed growth had accumulated by 80 DAS (fourth standard week), while in the second season, this occurred by 68 DAS. We do not have any direct evidence to support delayed pod initiation and lower growth rates in the first season, but it is possible that lower mean air temperatures until 28 January in the first season (10) could have delayed pod set. In the second season, temperatures started rising from 8 January, which could have influenced CGR and PGR. The effects of temperatures on initiation and growth processes of peanut are not clear in the literature (9). Initiation and growth of different plant organs may respond differently to temperature.

The $\mathrm{R}^{2}$ values for CGR and PGR in all treatments were above 0.9 and thus represent the best fit. Pod

Table 4. Pod yields, mean stomatal conductance (SC), crop growth rate (CGR), pod growth rate (PGR), and partitioning factor (PF) after the initiation of pod growth (68-156 DAS) in the 1981 to 1982 season.

\begin{tabular}{|c|c|c|c|c|c|}
\hline Treatment & Pod yield & $\mathrm{SC}$ & CGR & PGR & PF \\
\hline & kg ha $\mathbf{a}^{-1}$ & $\mathrm{~mm} \mathrm{~s}^{-1}$ & \multicolumn{2}{|c|}{$-g^{-2} \mathrm{~d}^{-1}-$} & $\%$ \\
\hline Control & 4720 & 10.4 & $\begin{array}{l}13.5 \\
(0.94) \dagger\end{array}$ & $\begin{array}{c}10.2 \\
(0.92)\end{array}$ & 75 \\
\hline A & 5300 & 11.5 & $\begin{array}{c}12.2 \\
(0.98)\end{array}$ & $\begin{array}{r}9.0 \\
(0.92)\end{array}$ & 74 \\
\hline B & 5300 & 11.3 & $\begin{array}{c}14.0 \\
(0.98)\end{array}$ & $\begin{array}{r}9.7 \\
(0.89)\end{array}$ & 69 \\
\hline $\mathrm{C}$ & 3210 & 9.0 & $\begin{array}{c}8.7 \\
(0.97)\end{array}$ & $\begin{array}{c}6.3 \\
(0.95)\end{array}$ & 72 \\
\hline $\operatorname{LSD}(0.05)$ & 681 & 0.22 & 2.31 & 2.93 & 7.1 \\
\hline
\end{tabular}

$\uparrow$ Values in parenthesis for CGRs and PGRs are $R^{2}$ of the regressions be tween DAS and respective dry matter.

$\ddagger$ LSD for the difference between the treatments. 
growth rates were higher in treatments $\mathrm{A}$ and $\mathrm{B}$ than in the control in the first season only. This rules out the possibility of increased PGR as the only factor contributing to the yield advantages observed in both seasons. Partitioning factors in our studies are comparable to that observed by Duncan et al. (5) for cv. Spancross. The PF was not affected by the early water stress treatments. Although the PF ranged from 69 to $76 \%$ in different treatments, these differences were not statistically significant.

Two physiological responses to pre-flowering drought that contributed to the increased yields in treatments A and B could be: (i) promotion of root growth during water stress (15), which promoted subsequent stomatal conductance and growth rates during podfill; and (ii) inhibition of the number of vegetative sites (leaves and branches). When stress was teleased, plants could set more fruiting sites with existing assimilates, since vegetative sites demanding assimilate supply are reduced. From this study it is apparent that the yield advantages due to moderate water deficits during the preflowering phase were associated with greater pod synchrony after the release of water stress, which resulted in the production of more mature pods combined with adequate canopy and CGR. Although the most stressed treatments had sink potential, the residual effects of stress on canopy development prevented these pods from realizing their potential.

\section{ACKNOWLEDGMENTS}

The authors wish to thank Drs. F. R. Bidinger and Duncan McDonald for their helpful comments on this paper, and Mr. K. Eswar for assisting in the growth analysis. $\therefore$

\section{REFERENCES}

1. Allen, L.H., Jr., K.J. Boote, and L.C. Hammond. 1976. Peanut stomatal diffusion resistance affected by soil water and solar radiation. Proc. Soil Crop Sci. Soc. Fla. 35:42-46.

2. Boote, K.J., and L.C. Hammond. 1981. Effect of drought on vegetative and reproductive development of peanut. Proc. Am. Peanut Res. Educ. Soc. 13:86 (Abstr).

3. ger. 1980. Photosynthesis of peanut canopies as affected by leaf spot and artificial defoliation. Agron. J. 72:247-252

4. rigation, water use, and water relations. p. 164-205. In H.E Pattee and C.T. Young (ed.) Peanut science and technology. Am. Peanut Res. and Educ. Soc., Yoakum, TX.

5. Duncan, W.G., D.E. McCloud, R.L. McGraw, and K.J. Boote. 1978. Physiological aspects of peanut yield improvement. Crop Sci. 18:1015-1020.

6. Gorbet, D.W., and F.M. Rhoads. 1975. Response of two peanut cultivars to irrigation and Kylar. Agron. J. 67:373-376.

7. Enyi, B.A.C. 1977. Physiology of grair yield in groundnuts ( $A r-$ achis hypogaea). Exp. Agric. 13:101-110.

8. Hanks, R.J., J. Keller, V.P. Rasmussen, and G.D. Wilson. 1976. Line source sprinkler for continuous variable irrigation crop production studies. Soil Sci. Soc. Am. J. 40:426-429.

9. Ketring, D.L., R.H. Brown, G.A. Sullivan, and B.B. Johnson. 1982. Growth physiology. p. 411 -457. In H.E. Pattee and C.T Young (ed.) Peanut science and technology. Am. Peanut Res. and Educ. Soc., Yoakum, TX.

10. Nageswara Rao, R.C., Sardar Singh, M.V.K. Sivakumar, K.L. Srivastava, and J.H. Williams. 1985. Effect of water deficit at different growth phases of peanut. I. Yield responses. Agron. J. 77:782-786.

11. Ochs, R., and T.M. Wormer. 1959. Influence de l'alimentation on eau sur la croissance de l'arachide. Oleagineaux 14:281-291.

12. Pallas, J.E., Jr., J.R. Stansell, and T.J. Koske. 1979. Effects of drought on Florunner peanuts. Agron. J. 71:853-858.

13. Reddi, G.H.S., and M.N. Reddy. 1977. Efficient use of irrigation water for wheat and groundnut. Mysore J. Agric. Sci. 11:2227.

14. Sanders, T.H., P.D. Blankenship, R.J. Cole, and R.A. Hill. 1982. Effects of drought and soil temperature on peanut canopy, stem and pod temperatures. Proc. Am. Peanut Res. Educ. Soc. 14:97 (Abstr).

15. Sarma, P.S. 1983. Soil-plant-water relations, growth and yield of groundnut (Arachis hypogaea) under moisture stress. F'h.D. diss. Andhra Pradesh Agric. Univ., Hyerabad, India.

16. Sivakumar, M.V.K., and P.S. Sarma. 1986. Studies on water relations of groundnut. p. 99-106. In Proc. of the Int. Symp. on Agrometeorology of Groundnut, Niamey, Niger. 21-26 Aug. 1985. ICRISAT, Patancheru, India.

17. Smith, B.W. 1954. Arachis hypogaea. Reproductive efficiency. Am. J. Bot. 41:607-616.

18. Stansell, J.R., J.L. Shepherd, J.E. Pallas, Jr., B.R. Bruce, N.A. Minton., D.K. Bell, and L.W. Morgan. 1976. Peanut responses to soil water variables in the south east. Peanut Sci. 3:44--48.

19. - , and J.E. Pallas, Jr. 1979. Peanut response to timing and duration of drought stress as reflected in kernel yield and quality. Proc. Am. Peanut Res. Educ. Soc. 11:61 (Abstr).

20. Vivekanandan, A.S., and H.P.M. Gunasena. 1976. Lysimetric studies on the effect of soil moisture tension on the growth and yield of maize (Zea mays L.) and groundnut (Arachis hypogaea L.). Beitr. Trop. Landwirtsch. Veterinaermed. 14:369-378.

21. Williams, J.H., J.H.H. Wilson, and G.C. Bate. 1975. The growth of groundnuts (Arachis hypogaea L. cv. Makulu Red) at three altitudes in Rhodesia. Rhod. J. Agric. Res. 13:33-43. 